\title{
Left atrial appendage closure in patients with a reduced left ventricular ejection fraction: results from the multicenter German LAARGE registry
}

\author{
Christian Fastner ${ }^{1,2,3}$. Johannes Brachmann ${ }^{4} \cdot$ Thorsten Lewalter $^{5} \cdot$ Uwe Zeymer $^{6} \cdot$ Horst Sievert $^{7,8}$.

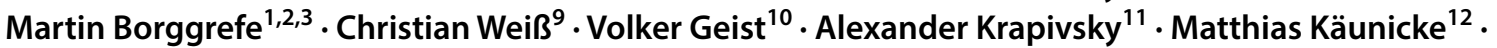 \\ Harald Mudra ${ }^{13}$. Matthias Hochadel ${ }^{14}$. Steffen Schneider ${ }^{14}$. Jochen Senges ${ }^{14}$. Ibrahim Akin ${ }^{1,2,3}$
}

Received: 23 October 2019 / Accepted: 4 March 2020 / Published online: 31 March 2020

(c) The Author(s) 2020

\begin{abstract}
Background Interventional left atrial appendage closure (LAAC) effectively prevents thromboembolic events in atrial fibrillation patients. Impaired left ventricular ejection fraction (LVEF) increases not only the thromboembolic risk but also the complication rates of cardiac interventions. The LAAC procedure's benefit in patients with an impaired LVEF, therefore, has yet to be investigated.

Methods LAARGE is a prospective, non-randomized registry depicting the clinical reality of LAAC in Germany. Procedure was conducted with different standard commercial devices, and follow-up period was one year. In the sense of an as-treated analysis, patients with started procedure and documented LVEF were selected from the whole database.

Results 619 patients from 37 centers were categorized into one of three groups: LVEF $>55 \%(56 \%), 36-55 \%$ (36\%), and $\leq 35 \%$ (8\%). Prevalence of cardiovascular comorbidity increased with LVEF reduction ( $p<0.001$ for trend). $\mathrm{CHA}_{2} \mathrm{DS}_{2}-\mathrm{VASc}$ score was 4.3, 4.8, and $5.1(p<0.001)$, and HAS-BLED score was 3.7, 4.1, and $4.2(p<0.001)$. Implantation success was consistently high (97.9\%), rates of intra-hospital MACCE (0.5\%), and other major complications $(4.2 \%)$ were low (each $p=\mathrm{NS}$ ). Kaplan-Meier estimation showed a decrease in survival free of stroke with LVEF reduction during one-year follow-up (89.3 vs. 87.0 vs. $79.8 \% ; p=0.067$ ), a trend which was no longer evident after adjustment for relevant confounding factors. Rates of non-fatal strokes ( 0.4 vs. 1.1 vs. $0 \%)$ and severe bleedings ( 0.7 vs. 0.0 vs. $3.1 \%)$ were consistently low across all groups (each $p=\mathrm{NS}$ ).
\end{abstract}

Electronic supplementary material The online version of this article (https://doi.org/10.1007/s00392-020-01627-8) contains supplementary material, which is available to authorized users.

Ibrahim Akin

ibrahim.akin@umm.de

1 First Department of Medicine, University Medical Centre Mannheim (UMM), Faculty of Medicine Mannheim, University of Heidelberg, Theodor-Kutzer-Ufer 1-3, 68167 Mannheim, Germany

2 European Center for AngioScience (ECAS), Mannheim, Germany

3 DZHK (German Center for Cardiovascular Research) Partner Site Heidelberg/Mannheim, Mannheim, Germany

4 Department of Cardiology, Angiology, and Pneumology, Second Medical Clinic, Coburg Hospital, Coburg, Germany

5 Department of Medicine, Cardiology, and Intensive Care, Hospital Munich-Thalkirchen, Munich, Germany

6 Klinikum Ludwigshafen, Ludwigshafen am Rhein, Germany
7 CardioVascular Center (CVC) Frankfurt, Frankfurt, Germany

8 Anglia Ruskin University, Chelmsford, UK

9 Department of Cardiology, Klinikum Lüneburg, Lüneburg, Germany

10 Department of Cardiology, Heart Center, Segeberger Kliniken, Bad Segeberg, Germany

11 Department of Cardiology, Evangelisches Krankenhaus, Mülheim (Ruhr), Germany

12 Department of Cardiology, University of Witten/Herdecke, Katholisches Klinikum Essen, Essen, Germany

13 Department of Cardiology, Klinikum Neuperlach, Munich, Germany

14 Stiftung Institut für Herzinfarktforschung, Ludwigshafen am Rhein, Germany 
Conclusions LVEF reduction neither influenced the procedural success nor the effectiveness and safety of stroke prevention by LAAC.

Trial Registration ClinicalTrials.gov Identifier: NCT02230748

\section{Graphic abstract}
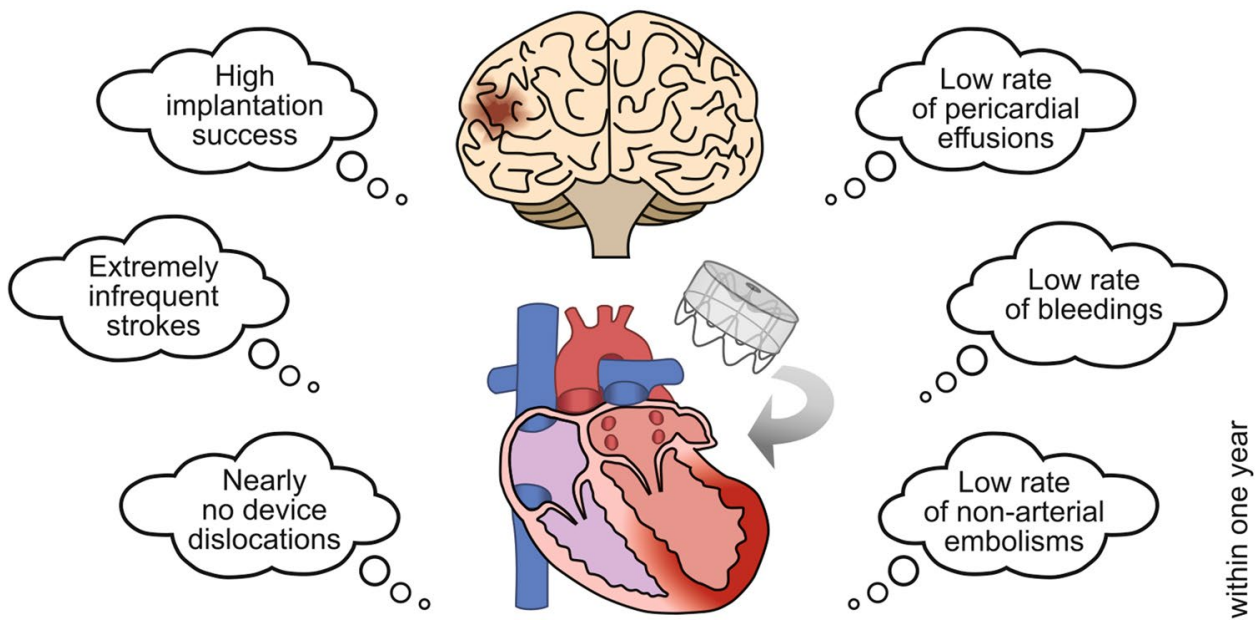

Keywords Atrial fibrillation - Ischemic stroke - Bleeding risk · LAA closure - Depressed left ventricular function · LAARGE

\begin{tabular}{|c|c|}
\hline \multicolumn{2}{|c|}{ Abbreviations } \\
\hline $\mathrm{AF}$ & Atrial fibrillation \\
\hline $\mathrm{CI}$ & Confidence interval \\
\hline DRT & Device-related thrombus \\
\hline HR & Hazard ratio \\
\hline IHF & Stiftung Institut für Herzinfarktforschung \\
\hline LA(A) & Left atrial (appendage) \\
\hline LAAC & Left atrial appendage closure \\
\hline LAARGE & $\begin{array}{l}\text { Left-Atrium-Appendage occluder } \\
\text { Register-GErmany }\end{array}$ \\
\hline (LV)EF & (Left ventricular) ejection fraction \\
\hline MACCE & $\begin{array}{l}\text { Major adverse cardiac and cerebrovascular } \\
\text { events }\end{array}$ \\
\hline OAC & Oral anticoagulation \\
\hline NS & Not significant \\
\hline TIA & Transient ischemic attack \\
\hline
\end{tabular}

\section{Introduction}

Atrial fibrillation (AF) is the most prevalent cardiac arrhythmia, with stroke and systemic embolization as prognostically relevant complications [1]. In AF patients with increased risk for thromboembolism, expressed by a $\mathrm{CHA}_{2} \mathrm{DS}_{2}$-VASc score $\geq 2$, a prophylactic treatment is urgently needed, and routinely performed with oral anticoagulants (OAC). However, in some patients, these drugs are contraindicated for different reasons [1-3]. For these cases, the interventional left atrial appendage closure (LAAC) has evolved as the therapy of choice [1].

$\mathrm{AF}$ and heart failure due to a reduced left ventricular ejection fraction (LVEF) frequently coexist [4]. The prevalence of AF increases with the New York Heart Association (NYHA) functional class, so that nearly $5 \%$ of patients present with AF in NYHA functional class I, and almost $50 \%$ of patients in NYHA functional class IV [5]. AF patients with a severely reduced LVEF have a markedly increased risk for thromboembolic complications [6]. Therefore, there is a great need for effective thromboembolic prophylaxis especially in these patients. Data on periprocedural complications regarding cardiac interventions in patients with impaired LVEF are inconsistent [7, 8]. For example, patients with reduced LVEF are at a higher risk for device thrombosis [9]. After LAA closure, with regard to the long-term follow-up, the achievement of the primary efficacy endpoint was consistent for patients with LVEF $\geq 60 \%$ and those with impaired LVEF in the PROTECT-AF study [10]. However, in this study, patients with an LVEF $<30 \%$ were excluded by protocol, and the authors stated that this was due to the fact that the intervention in the LAA was naturally insufficient to prevent thromboembolism from the highly impaired left ventricle (LV). Nonetheless, patients with reduced LVEF are at risk of left atrial (LA) cavity thrombi [11]. A site-specific technique of thromboembolic prophylaxis with subsequent 
cessation of systemic anticoagulation might, therefore, be associated with an increased thromboembolic risk; yet, this is not officially specified as contraindication for this procedure.

The present subanalysis of the Left-Atrium-Appendage occluder Register-GErmany (LAARGE; ClinicalTrials.gov Identifier: NCT02230748) aimed to investigate procedural and one-year outcome of LAAC patients with and without LV dysfunction.

\section{Methods}

\section{Enrollment and conduction of procedure}

LAARGE is a prospective, multicenter real-world registry, which enrolled patients from 37 centers. It had been designed to compile a large database on daily practice of LAAC and clinical follow-up data. Recruitment started in July 2014, and ended in January 2016. Patients which were scheduled for an LAAC were consecutively included in the LAARGE database. Cases with started procedure and documented LVEF were included in the present subanalysis (as-treated analysis). The indication was set by the attending cardiologist in consideration of the dedicated guidelines [1], and the patients were treated according to the current recommendations and the manufacturer's instructions with different post-market devices [12]. The postprocedural management including the antithrombotic treatment was at the discretion of the operating physician [13]. The study was carried out according to the principles of the 1975 Declaration of Helsinki, and was approved by the ethics committee of the Landesärztekammer Rheinland-Pfalz. Written informed consent to participate in the registry was obtained from all patients.

\section{Definition of reduced LVEF}

LVEF dysfunction was defined as an LVEF 36-55\% meaning a moderate reduction (mrLVEF), and $\leq 35 \%$ meaning a severe reduction ( $\mathrm{srLVEF}$ ).

\section{Data acquisition}

Baseline characteristics, imaging, and procedural data as well as intra-hospital complications were reported by each center based on an electronic case report form. Adverse events and complications during the one-year follow-up were registered by the Stiftung Institut für Herzinfarktforschung (IHF) via a standardized phone interview with each patient, and by reports from the implantation centers. In the case of relevant complications, original medical records were reviewed by an event adjudication committee to allow similar assessment of all events. If patients could not be contacted, information was obtained from the residents' registration offices.

\section{Outcome measures}

Effectiveness was primarily assessed by the absence of allcause death and stroke during follow-up, secondarily by the absence of systemic embolism and transient ischemic attacks (TIA). Intra-hospital complications including para-device leaks $>5 \mathrm{~mm}$ as well as severe and moderate bleedings, and device dislocations during follow-up constituted the safety outcome measure. Implantation success was defined as a stable device anchorage.

\section{Statistics}

Statistical analyses were performed with SAS ${ }^{\circledR}$ version 9.4 (SAS Institute, Cary, NC, USA). Continuous data are presented as means with standard deviation, or as medians with interquartile ranges (25th and 75th percentiles), categorical data as frequencies with group-related percentages. Trends across the patient groups were assessed by a Cochran-Armitage test regarding categorical variables, or by an exact Cochran-Armitage test in case of rare events, and by a Jonckheere-Terpstra test regarding metrical variables, as indicated in the tables. In addition, the group with srLVEF was compared with the rest using the Pearson chi-squared test, Fisher's exact test, or Mann-Whitney-Wilcoxon test for categorical variables, rare events, and metrical variables, respectively. These statistics were based on the available cases.

One-year mortality after the implantation procedure, and the incidence of the combined event of all-cause death or non-fatal stroke were evaluated by means of survival analysis. Hazard ratios (HR) with 95\% confidence intervals (CI) were estimated using Cox regression without adjustment, and adjusted for baseline risk factors significantly associated with LV function: age (linear), sex, coronary artery disease, peripheral arterial disease, chronic kidney disease, and diabetes mellitus. Expected yearly rates of non-fatal stroke were calculated from the individual $\mathrm{CHA}_{2} \mathrm{DS}_{2}$-VASc score, respectively [14]. The follow-up duration was defined as the time span from index discharge to the date of the follow-up contact. $p$ values $\leq 0.05$ (two-tailed) were considered significant.

\section{Results}

\section{Baseline characteristics}

619 patients with documented LVEF were included in this subanalysis. $344(55.6 \%)$ revealed a preserved (p) LVEF, $225(36.3 \%)$ an mrLVEF, and $50(8.1 \%)$ an 
srLVEF (Table 1). Patients were predominantly older than 64 years of age $(91.4 \% ; p=\mathrm{NS})$. Among srLVEF patients male sex, coronary artery disease, and renal impairment were more prevalent (each $p<0.01$ ). Both $\mathrm{CHA}_{2} \mathrm{DS}_{2}$-VASc $(4.3 \pm 1.5,4.8 \pm 1.6$, and $5.1 \pm 1.5$, respectively; $p<0.001$ for trend) and HAS-BLED score $(3.7 \pm 1.1,4.1 \pm 1.2$ and $4.2 \pm 1.0$, respectively; $p<0.001$ for trend) were the highest in the srLVEF group. Across all groups, the main indication was a prior bleeding event $(80.0 \% ; p=\mathrm{NS}$ for trend).

The LA diameter increased with decreasing LVEF $(p<0.001$ for trend; supplemental Table 1). No LAA morphology was predominant in any group.

\section{Procedural data and intra-hospital complications}

Implantation success was achieved in $97.9 \%$, and was independent from LVEF ( $p=$ NS for trend; Table 2). No peridevice leak $>5 \mathrm{~mm}$ was evident. Two interruptions were not related to LAA anatomy: in one patient, the transseptal sheath was destroyed intraprocedurally; the other patient developed an ST-segment elevation myocardial infarction. In an additional two patients, technical success was only achieved in a second procedure. There was no significant trend in the use of device types. $44.6 \%$ received a WATCH-

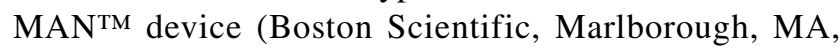
USA), $27.5 \%$ an AMPLATZER ${ }^{\text {TM }}$ Cardiac Plug, and $24.9 \%$ an AMPLATZER ${ }^{\mathrm{TM}}$ Amulet ${ }^{\mathrm{TM}}$ (both Abbott, Chicago, IL,

Table 1 Baseline characteristics

\begin{tabular}{|c|c|c|c|c|}
\hline & pLVEF & mrLVEF & srLVEF & $p$ value* \\
\hline Total cohort, $n$ ( $\%$ of all patients) & $344(55.6)$ & $225(36.3)$ & $50(8.1)$ & - \\
\hline Male sex, $n(\%)$ & $196(57.0)$ & $142(63.1)$ & $40(80.0)$ & $\mathbf{0 . 0 0 2}^{\#}$ \\
\hline Age [years], median (IQR) & $76(72 ; 80)$ & $78(73 ; 83)$ & $77(73 ; 81)$ & 0.019 \\
\hline Body mass index $\left[\mathrm{kg} / \mathrm{m}^{2}\right]$, median (IQR) & $26(24 ; 30)$ & $27(24 ; 30)$ & $27(25 ; 29)$ & 0.66 \\
\hline $\mathrm{CHA}_{2} \mathrm{DS}_{2}$-VASc score, mean $\pm \mathrm{SD}$ & $4.3 \pm 1.5$ & $4.8 \pm 1.6$ & $5.1 \pm 1.5$ & $<0.001^{\sharp}$ \\
\hline HAS-BLED score, mean \pm SD & $3.7 \pm 1.1$ & $4.1 \pm 1.2$ & $4.2 \pm 1.0$ & $<0.001^{\ddagger}$ \\
\hline Arterial hypertension, $n(\%)$ & $325(94.5)$ & $206(91.6)$ & $44(88.0)$ & 0.054 \\
\hline Diabetes mellitus, $n(\%)$ & $103(29.9)$ & $87(38.7)$ & $22(44.0)$ & 0.009 \\
\hline \multicolumn{5}{|l|}{ Prior cerebrovascular event, each $n(\%)$} \\
\hline TIA & $34(9.9)$ & $15(6.7)$ & $2(4.0)$ & 0.076 \\
\hline Stroke & $73(21.2)$ & $49(21.8)$ & $9(18.0)$ & 0.77 \\
\hline Coronary heart disease, $n(\%)$ & $121(35.2)$ & $129(57.3)$ & $36(72.0)$ & $<\mathbf{0 . 0 0 1}^{\sharp}$ \\
\hline eGFR [MDRD], median (IQR) & $65.4(48.3 ; 81.5)$ & $54.3(36.4 ; 77.5)$ & $49.1(36.0 ; 79.7)$ & $<\mathbf{0 . 0 0 1}^{\ddagger}$ \\
\hline Prior severe bleeding event, $n(\%)$ & $128(37.2)$ & $94(41.8)$ & $25(50.0)$ & 0.067 \\
\hline \multicolumn{5}{|l|}{ Type of AF, each $n(\%)$} \\
\hline Paroxysmal & $151(43.9)$ & $88(39.1)$ & $22(44.0)$ & 0.52 \\
\hline Persistent & $59(17.2)$ & $42(18.7)$ & $9(18.0)$ & 0.71 \\
\hline Permanent & $134(39.0)$ & $95(42.2)$ & $19(38.0)$ & 0.72 \\
\hline \multicolumn{5}{|l|}{ Indication for LAAC, each $n(\%)$} \\
\hline Prior bleeding & $270(78.5)$ & $186(82.7)$ & $39(78.0)$ & 0.52 \\
\hline $\begin{array}{l}\text { Prior cerebrovascular event despite anticoagula- } \\
\text { tion }\end{array}$ & $98(28.5)$ & $59(26.2)$ & $10(20.0)$ & 0.22 \\
\hline Adverse drug reaction & $66(19.2)$ & $42(18.7)$ & $11(22.0)$ & 0.81 \\
\hline Labile INR & $26(7.6)$ & $23(10.2)$ & $4(8.0)$ & 0.48 \\
\hline Incompliance with anticoagulation & $19(5.5)$ & $12(5.3)$ & $2(4.0)$ & 0.71 \\
\hline Patient's preference & $97(28.2)$ & $52(23.1)$ & $11(22.0)$ & 0.15 \\
\hline Other reason & $31(9.0)$ & $19(8.4)$ & $5(10.0)$ & 0.98 \\
\hline \multicolumn{5}{|l|}{ Medication at presentation, each $n(\%)$} \\
\hline Anticoagulation & $201(58.4)$ & $138(61.3)$ & $36(72.0)$ & 0.093 \\
\hline Antiplatelet agent & $110(32.0)$ & $83(36.9)$ & $24(48.0)$ & $\mathbf{0 . 0 2 5}^{\#}$ \\
\hline
\end{tabular}

$A F$ atrial fibrillation, $e G F R$ estimated glomerular filtration rate, INR international normalized ratio, IQR interquartile range, $L A A C$ left atrial appendage closure, $L V E F$ left ventricular ejection fraction, $M D R D$ modification of diet in renal disease, $S D$ standard deviation, $T I A$ transient ischemic attack

*Tested by Cochran-Armitage or Jonckheere-Terpstra test ( $p \leq 0.05$ is indicating a significant difference); \#significant difference between LVEF $\leq 35 \%$ and $>35 \%$ ( $p \leq 0.05$; tested by Pearson chi-squared or Mann-Whitney-Wilcoxon test) 
Table 2 Procedural data

\begin{tabular}{|c|c|c|c|c|}
\hline & pLVEF & mrLVEF & srLVEF & $p$ value* \\
\hline Total cohort, $n$ (\% of all patients) & $344(55.6)$ & $225(36.3)$ & $50(8.1)$ & - \\
\hline Successful implantation, $n(\%)$ & $336(97.7)$ & $221(98.2)$ & $49(98.0)$ & 0.72 \\
\hline Number of implantation attempts, mean \pm SD & $1.7 \pm 1.3$ & $1.6 \pm 1.2$ & $1.5 \pm 0.9$ & 0.96 \\
\hline Peri-device leak, each $n(\%)$ & $17(5.1)$ & $14(6.3)$ & $1(2.0)$ & 0.91 \\
\hline$<3 \mathrm{~mm}$ & 13 & 10 & 1 & \\
\hline $3-5 \mathrm{~mm}$ & 4 & 4 & 0 & \\
\hline$>5 \mathrm{~mm}$ & 0 & 0 & 0 & \\
\hline \multicolumn{5}{|l|}{ Type of LAAC device, each $n(\%)$} \\
\hline WATCHMAN'M & $164(47.7)$ & $90(40.0)$ & $22(44.0)$ & 0.16 \\
\hline AMPLATZER ${ }^{\mathrm{TM}}$ Cardiac Plug & $93(27.0)$ & $59(26.2)$ & $18(36.0)$ & 0.43 \\
\hline AMPLATZER $^{\mathrm{TM}}$ Amulet $^{\mathrm{TM}}$ & $75(21.8)$ & $69(30.7)$ & $10(20.0)$ & 0.25 \\
\hline Other device & $12(3.5)$ & $7(3.1)$ & $0(0.0)$ & 0.36 \\
\hline Total duration [min], median (IQR) & $60(45 ; 80)$ & $57(41 ; 76)$ & $60(43 ; 81)$ & 0.32 \\
\hline Fluoroscopy time [min], median (IQR) & $11(7 ; 15)$ & $10(7 ; 15)$ & $9(6 ; 15)$ & 0.36 \\
\hline Dose-area product $\left[\mathrm{Gy} * \mathrm{~cm}^{2}\right]$, median (IQR) & $1821(638 ; 4011)$ & $2303(1027 ; 4226)$ & $3187(1279 ; 5784)$ & $\mathbf{0 . 0 0 4}^{\#}$ \\
\hline \multicolumn{5}{|l|}{ Sedation type, each $n(\%)$} \\
\hline Conscious sedation & $287(83.4)$ & $193(85.8)$ & $39(78.0)$ & 0.85 \\
\hline General anesthesia & $40(11.6)$ & $21(9.3)$ & $11(22.0)$ & 0.30 \\
\hline Other & $10(2.9)$ & $7(3.1)$ & $0(0.0)$ & 0.36 \\
\hline None & $7(2.0)$ & $4(1.8)$ & $0(0.0)$ & 0.40 \\
\hline
\end{tabular}

$I Q R$ interquartile range, $L A A C$ left atrial appendage closure, $L V E F$ left ventricular ejection fraction, $S D$ standard deviation

*Tested by Cochran-Armitage or Jonckheere-Terpstra test ( $p \leq 0.05$ is indicating a significant difference); " significant difference between LVEF $\leq 35 \%$ and $>35 \%$ ( $p \leq 0.05$; tested by Pearson chi-squared or Mann-Whitney-Wilcoxon test)

USA). Except from dose-area product, which increased with LVEF reduction ( $p=0.004$ for trend), procedural parameters were statistically indifferent across all groups.

Intra-hospital complications, especially major adverse cardiac and cerebrovascular events (MACCE), and other major complications were throughout infrequent, and showed a balanced distribution (Table 3). Two patients died due to an unknown or a cardiovascular reason other than the implant procedure, respectively, and the cases of death were hence classified as adverse events. Eight dislodged devices could be snared by a catheter (each $p=\mathrm{NS}$ for trend). Pursuant to this low number of complications, the period of hospitalization was generally short (median 2 days; $p=\mathrm{NS}$ for trend).

$12.2 \%$ of patients received anticoagulants at hospital discharge ( $p=$ NS for trend; supplemental Table 2). Patients who received dual antiplatelet agents were prescribed this therapy for 3-6 months after the procedure ( $p=$ NS for trend), while the majority of these patients (59.0\%) stayed on this medication for only 3 months.

\section{One-year follow-up}

For 602 patients ( $97.6 \%$ of all patients who had been discharged alive), a follow-up was documented ( $p=$ NS for trend; Table 4). The combined primary effectiveness outcome measure, i.e., absence of all-cause death and non-fatal stroke, was reached in $87.7 \%$ of patients within 365 days after the procedure ( $p=0.067$ for trend; Fig. 1$)$. In a simple Cox regression model, an increased incidence of all-cause death or stroke in the srLVEF group compared to the pLVEF group was evident. However, after adjustment for age, sex, chronic kidney disease, coronary artery disease, peripheral arterial disease, and diabetes mellitus, the effect of LVEF on the combined effectiveness outcome measure did not reach statistical significance any more (Table 5). In contrast, chronic kidney disease (HR: 3.18 ; 95\% CI: $1.90-5.32 ; p<0.001)$, coronary artery disease (HR: 1.86 ; 95\% CI: $1.03-3.33 ; p=0.038)$, and peripheral arterial disease (HR: 1.72 ; 95\% CI: $1.04-2.86 ; p=0.035$ ) were identified as independent predictors. Thromboembolic events were generally rare: non-fatal ischemic strokes occurred in $0.6 \%$ of patients, TIA in $0.4 \%$, and systemic embolisms in $0.2 \%$ (each $p=\mathrm{NS}$ for trend). This was despite the fact that only $5.9 \%$ of patients who persisted on OAC after 1 year $(p=\mathrm{NS}$ for trend), whereby the distribution of anticoagulant agents did not differ between the groups (supplemental Table 2). In one pLVEF patient with a WATCHMAN ${ }^{\mathrm{TM}}$ device, a devicerelated thrombus (DRT) was detected after 1.5 months by transesophageal echocardiography (information reported for 217 patients from 20 centers, $p=$ NS between LVEF groups; 
Table 3 Intra-hospital outcome

\begin{tabular}{lcrll}
\hline & pLVEF & mrLVEF & srLVEF & $p$ value* \\
\hline Total cohort, $n$ (\% of all patients) & $344(55.6)$ & $225(36.3)$ & $50(8.1)$ & - \\
MACCE, $n(\%)$ & $1(0.3)$ & $2(0.9)$ & $0(0.0)$ & 1.00 \\
Death, $n(\%)$ & $1(0.3)$ & $1(0.4)$ & $0(0.0)$ & 1.00 \\
Myocardial infarction, $n(\%)$ & $0(0.0)$ & $1(0.4)$ & $0(0.0)$ & 1.00 \\
Stroke, $n$ (\%) & $0(0.0)$ & $1(0.4)$ & $0(0.0)$ & 1.00 \\
Other major complications, $n(\%)$ & $14(4.1)$ & $11(4.9)$ & $1(2.0)$ & 0.88 \\
Severe bleeding, $n(\%)$ & $3(0.9)$ & $3(1.3)$ & $1(2.0)$ & 0.55 \\
AV fistula or pseudoaneurysm, $n(\%)$ & $3(0.9)$ & $3(1.3)$ & $0(0.0)$ & 1.00 \\
Pericardial effusion requiring action, each $n(\%)$ & & & & \\
Surgery & $1(0.3)$ & $1(0.4)$ & $0(0.0)$ & 1.00 \\
Intervention & $7(2.0)$ & $5(2.2)$ & $1(2.0)$ & 1.00 \\
Device dislodgement requiring action, each $n(\%)$ & $1(0.3)$ & $1(0.4)$ & $0(0.0)$ & 1.00 \\
Moderate complications, $n(\%)$ & $32(9.3)$ & $21(9.3)$ & $6(12.0)$ & 0.67 \\
Moderate bleeding, $n(\%)$ & $6(1.7)$ & $3(1.3)$ & $2(4.0)$ & 0.64 \\
TIA, $n$ (\%) & $0(0.0)$ & $0(0.0)$ & $0(0.0)$ & - \\
Successful cardiopulmonary resuscitation, $n(\%)$ & $2(0.6)$ & $1(0.4)$ & $0(0.0)$ & 0.70 \\
Access site infection, $n(\%)$ & $1(0.3)$ & $0(0.0)$ & $0(0.0)$ & 0.64 \\
Pericardial effusion with conservative treatment, $n(\%)$ & $5(1.5)$ & $6(2.7)$ & $0(0.0)$ & 1.00 \\
Device dislodgement handled by immediate retraction, $n$ & $4(1.2)$ & $2(0.9)$ & $0(0.0)$ & 0.55 \\
(\%) & & & & \\
\hline
\end{tabular}

$A V$ arteriovenous, $L V E F$ left ventricular ejection fraction, $M A C C E$ major adverse cardiac and cerebrovascular events, TIA transient ischemic attack

*Tested by exact Cochran-Armitage test ( $p \leq 0.05$ is indicating a significant difference)

Table 4 One-year follow-up

\begin{tabular}{|c|c|c|c|c|}
\hline & pLVEF & mrLVEF & srLVEF & $p$ value* \\
\hline Discharged alive, $n$ & 343 & 224 & 50 & \\
\hline Information on vital status obtained, $n(\%)$ & $331(96.5)$ & $221(98.7)$ & $50(100.0)$ & 0.064 \\
\hline Death within 365 days, $n$ (\% of patients with documented vital status) & $33(10.0)$ & $24(10.9)$ & $10(20.0)$ & $0.096^{\#}$ \\
\hline \multicolumn{5}{|l|}{ Events in survivors of follow-up (365 days) } \\
\hline Surviving patients with detailed follow-up information, $n$ & 282 & 183 & 32 & \\
\hline \multicolumn{5}{|l|}{ Major adverse events } \\
\hline Stroke, $n(\%)$ & $1(0.4)$ & $2(1.1)$ & $0(0.0)$ & 0.64 \\
\hline TIA, $n(\%)$ & $1(0.4)$ & $1(0.5)$ & $0(0.0)$ & 1.00 \\
\hline Systemic embolism, $n(\%)$ & $1(0.4)$ & $0(0.0)$ & $0(0.0)$ & 1.00 \\
\hline \multicolumn{5}{|l|}{ Device dislodgement requiring action, each $n(\%)$} \\
\hline Surgery & $2(0.7)$ & $0(0.0)$ & $0(0.0)$ & 0.58 \\
\hline Additional intervention & $2(0.7)$ & $0(0.0)$ & $0(0.0)$ & 0.58 \\
\hline Pericardial effusion requiring action, $n(\%)$ & $1(0.4)$ & $0(0.0)$ & $0(0.0)$ & 1.00 \\
\hline Severe groin complication, $n(\%)$ & $1(0.4)$ & $1(0.5)$ & $1(3.1)$ & 0.17 \\
\hline Pulmonary embolism, $n(\%)$ & $2(0.7)$ & $3(1.6)$ & $1(3.1)$ & 0.19 \\
\hline Severe bleeding, $n(\%)$ & $2(0.7)$ & $0(0.0)$ & $1(3.1)$ & 0.64 \\
\hline \multicolumn{5}{|l|}{ Moderate adverse events } \\
\hline Deep vein thrombosis, $n(\%)$ & $0(0.0)$ & $2(1.1)$ & $0(0.0)$ & 0.26 \\
\hline Moderate bleeding, $n(\%)$ & $10(3.5)$ & $8(4.4)$ & $2(6.3)$ & 0.46 \\
\hline Rehospitalization, $n(\%)^{\circ}$ & $94(37.2)$ & $69(42.6)$ & $10(33.3)$ & 0.70 \\
\hline
\end{tabular}

LVEF left-ventricular ejection fraction, TIA transient ischemic attack

*Tested by exact Cochran-Armitage (events) or asymptotic Cochran-Armitage test ( $p<0.05$ is indicating a significant difference); ${ }^{\#}$ significant difference between LVEF $\leq 35 \%$ and $>35 \%$ ( $p<0.05$; tested by Fisher's exact test); ${ }^{\circ}$ data available for 253 (pLVEF), 162 (mrLVEF), and 30 (srLVEF) patients, respectively 


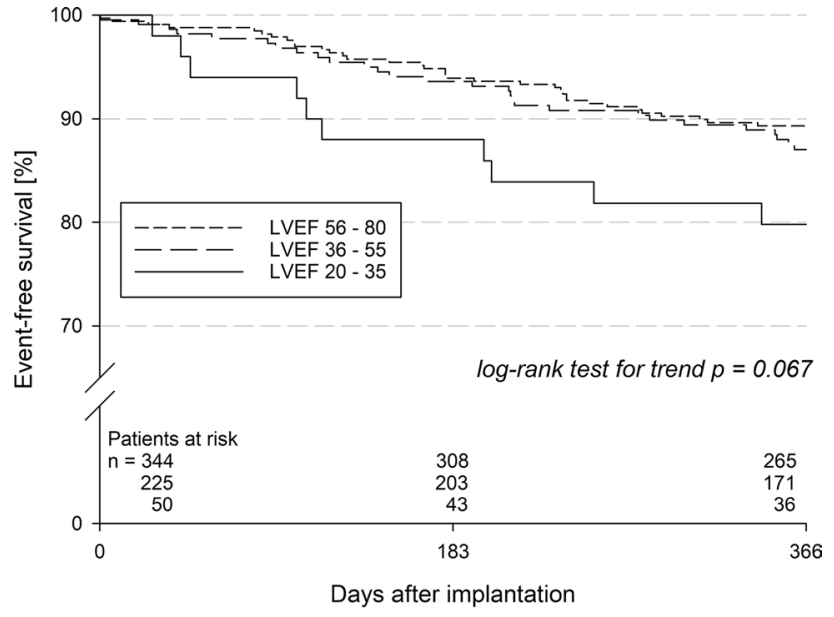

Kaplan-Meier analyses for pLVEF (dashed line), mrLVEF (broadly dashed line), and srLVEF patients (solid line)

Fig. 1 Freedom from all-cause death and non-fatal stroke after left atrial appendage closure

Table 5 Cox regression analysis for the primary effectiveness outcome measure

\begin{tabular}{llll}
\hline & Hazard ratio & $95 \%$ CI & $p$ value \\
\hline $\begin{array}{llll}\text { Unadjusted effects } \\
\text { LVEF } \leq 35 \%\end{array}$ & & & \\
LVEF 36-55\% & 1.04 & $1.01-4.11$ & 0.138 \\
Adjusted effects* & & $0.74-2.01$ & \\
LVEF $\leq 35 \%$ & 1.09 & & \\
LVEF 36-55\% & 0.84 & $0.53-2.27$ & 0.690 \\
\hline
\end{tabular}

$C I$ confidence interval, $L V E F$ left ventricular ejection fraction

*Adjusted for age (linear), sex, chronic kidney disease, coronary artery disease, peripheral arterial disease, and diabetes mellitus; $p \leq 0.05$ indicates significant difference

median time point $1.3(2.7 ; 5.7)$ months). The DRT could be resolved by resumption of phenprocoumon for three months. No further thromboembolic event was registered in this patient during follow-up.

Concerning the safety outcome measures, the rates of device dislocations $(0.8 \%)$, severe $(0.6 \%)$, and moderate (4.0\%) bleedings were low, and independent of LVEF. Three patients needed blood transfusions. Moreover, thromboembolisms in the venous system were rare events $(1.6 \%, p=\mathrm{NS}$ for trend).

\section{Discussion}

The present subanalysis of the multicenter LAARGE registry revealed that the effectiveness of stroke prevention by LAAC is high and persistent in AF patients with LV myocardial impairment. Despite srLVEF patients being prone to a preexisting relevantly increased thromboembolic risk [6], this finding was also applicable to this subgroup of patients.

Though prima facie, the combined event rate of allcause deaths and non-fatal strokes showed a trend towards a higher incidence with LVEF reduction, this only reflects the expectable accompanying increase in cardiovascular comorbidity. Consistently, LVEF impairment was associated with an increase in $\mathrm{CHA}_{2} \mathrm{DS}_{2}$-VASc score $(4.3,4.8$ and 5.1, respectively). It is, therefore, not remarkable that all-cause deaths were accountable for at least $95.7 \%$ of the events in the primary outcome measure. After adjustment for relevant confounders, a significant difference between the LVEF groups was no longer evident. Moreover, the observed annual stroke rates $(0.4 \%$ in pLVEF, $1.1 \%$ in mrLVEF, and $0 \%$ in srLVEF patients, respectively) were substantially reduced, especially when compared to the annual rates estimated by the $\mathrm{CHA}_{2} \mathrm{DS}_{2}$-VASc score (5.4\% in pLVEF, $6.2 \%$ in mrLVEF, and $6.7 \%$ in srLVEF patients, respectively) [14]. TIAs $(0.4 \%)$ and systemic embolisms $(0.2 \%)$ were absolutely infrequent across all groups.

Such a low rate of thromboembolism was reached although patients with severely impaired LV myocardium were not anticoagulated to a higher extent after the procedure, neither did they present with a higher percentage of prior strokes at baseline. These findings could extend the evidence that OAC is dispensable in those patients with regard to LV thromboembolism [10, 15]. Though one must bear in mind that the present results are limited to one year, and thromboembolic complications might occur later on.

Across all groups, implantation success (97.9\%), i.e., stable device anchorage without a relevant peri-device leak, was very high compared to the initial trials on LAAC [16, 17], irrespective of a diversified prior experience of the participating operators. Similar technical feasibility was also reflected by a resembling procedural duration and fluoroscopy time. Unlike in other cardiac interventions [7, 18], LAAC was not accompanied by an elevated rate of periprocedural complications or deaths in patients with reduced LVEF. Especially MACCE, but also other major complications were not only infrequent ( 0.5 and $4.2 \%$, respectively), but also comparably distributed between the LVEF groups, and the frequencies were in line with other recently published data $[19,20]$. These low complication rates might be due to leaving out the high-pressure LV system, or the ventricular myocardium from the intervention.

Together with a consistently low rate of periprocedural complications, major bleedings $(0.6 \%)$ and non-arterial thromboembolic events (1.6\%) were infrequent during follow-up, and constituted for adequate safety.

For the first time, the well-established LAAC intervention was shown to not only come along with high procedural success across all stages of LVEF, but also to 
guarantee excellent stroke prophylaxis irrespective of LV myocardial impairment. In summary, there was no evidence which justifies excluding patients with reduced EF from this intervention.

\section{Limitations}

These analyses were based on data of a real-world registry with some inherent limitations. Respecting the observational character of this registry, conduction of the intervention was not influenced by the study investigators, and was based on the operators' discretions as well as the manufacturers' recommendations. This individualized decision algorithm might have influenced the outcome measures, but surely reflects the clinical practice. There is no information about the implantation volume per center and per operator during the study period. Adverse events during follow-up were partly self-reported, which might have lessened the detected numbers. The individual reason for a maintained anticoagulation after the procedure could not be extracted from the original data. In addition, the follow-up was limited to one year. However, despite the limitations of this observational registry, it is serving as a data source for a little studied topic.

\section{Conclusion}

Neither the procedural success nor the periprocedural complication rate was influenced by LV systolic function. Despite a diversified risk profile at baseline, annual rates of non-fatal strokes and major bleedings were low across all groups, which meant a substantial risk reduction as compared to the estimated risks. LAAC, therefore, appeared as a feasible intervention in AF patients with reduced LVEF.

Acknowledgements Open Access funding provided by Projekt DEAL.

Funding The LAARGE registry was funded by the Stiftung Institut für Herzinfarktforschung (IHF; Ludwigshafen am Rhein, Germany). The present work was supported by an unrestricted grant from Boston Scientific (Marlborough, MA, USA).

\section{Compliance with ethical standards}

Conflict of interest Johannes Brachmann reports grants and personal fees from Biotronik (Berlin, Germany), Medtronic (Dublin, Ireland), Pfizer (New York City, NY, USA), and St. Jude Medical (Saint Paul, MN, USA). Horst Sievert reports study honoraria to institution, payment of travel expenses, consulting fees (personal honoraria had not been paid) from Abbott (Chicago, IL, USA), Boston Scientific (Marlborough, MA, USA), Lifetech (Nanshan District, Shenzhen, China), and Occlutech (Jena, Germany). Matthias Käunicke reports personal fees from Boston Scientific (Marlborough, MA, USA). Matthias Hochadel, Steffen Schneider, and Jochen Senges report unrestricted grants from Boston Scientific (Marlborough, MA, USA) for performing statistical analyses. Christian Fastner, Thorsten Lewalter, Uwe Zeymer, Martin Borggrefe, Christian Weiß, Volker Geist, Alexander Krapivsky, Harald Mudra, and Ibrahim Akin do not report any relevant conflicts of interest.

Open Access This article is licensed under a Creative Commons Attribution 4.0 International License, which permits use, sharing, adaptation, distribution and reproduction in any medium or format, as long as you give appropriate credit to the original author(s) and the source, provide a link to the Creative Commons licence, and indicate if changes were made. The images or other third party material in this article are included in the article's Creative Commons licence, unless indicated otherwise in a credit line to the material. If material is not included in the article's Creative Commons licence and your intended use is not permitted by statutory regulation or exceeds the permitted use, you will need to obtain permission directly from the copyright holder. To view a copy of this licence, visit http://creativecommons.org/licenses/by/4.0/.

\section{References}

1. Kirchhof P, Benussi S, Kotecha D, Ahlsson A, Atar D, Casadei B, Castella M, Diener HC, Heidbuchel H, Hendriks J, Hindricks G, Manolis AS, Oldgren J, Popescu BA, Schotten U, Van Putte B, Vardas P (2016) 2016 ESC Guidelines for the management of atrial fibrillation developed in collaboration with EACTS. Eur Heart J 37(38):2893-2962. https://doi.org/10.1093/eurheartj/ ehw210

2. D'Ancona G, Safak E, Ince H (2019) Left atrial appendage occlusion in patients with atrial fibrillation and high risk of fall: a clinical dilemma or a budgetary issue? Clin Res Cardiol 108(12):1406-1407. https://doi.org/10.1007/s00392-019-01476 $-0$

3. Hohnloser SH, Basic E, Nabauer M (2017) Comparative risk of major bleeding with new oral anticoagulants (NOACs) and phenprocoumon in patients with atrial fibrillation: a post-marketing surveillance study. Clin Res Cardiol 106(8):618-628. https://doi. org/10.1007/s00392-017-1098-x

4. Thihalolipavan S, Morin DP (2015) Atrial fibrillation and heart failure: update 2015. Prog Cardiovasc Dis 58(2):126-135. https ://doi.org/10.1016/j.pcad.2015.07.004

5. Maisel WH, Stevenson LW (2003) Atrial fibrillation in heart failure: epidemiology, pathophysiology, and rationale for therapy. Am J Cardiol 91(6):2-8

6. Abraham JM, Connolly SJ (2014) Atrial fibrillation in heart failure: stroke risk stratification and anticoagulation. Heart Fail Rev 19(3):305-313. https://doi.org/10.1007/s10741-014-9420-4

7. Schymik G, Tzamalis P, Herzberger V, Bergmann J, Bramlage P, Wurth A, Conzelmann LO, Luik A, Schrofel H (2017) Transcatheter aortic valve implantation in patients with a reduced left ventricular ejection fraction: a single-centre experience in 2000 patients (TAVIK Registry). Clin Res Cardiol 106(12):1018-1025. https://doi.org/10.1007/s00392-017-1151-9

8. Geis NA, Puls M, Lubos E, Zuern CS, Franke J, Schueler R, von Bardeleben RS, Boekstegers P, Ouarrak T, Zahn R, Ince H, Senges J, Katus HA, Bekeredjian R (2018) Safety and efficacy of MitraClip therapy in patients with severely impaired left ventricular ejection fraction: results from the German transcatheter mitral valve interventions (TRAMI) registry. Eur J Heart Fail 20(3):598-608. https://doi.org/10.1002/ejhf.910

9. Plicht B, Konorza TF, Kahlert P, Al-Rashid F, Kaelsch H, Janosi RA, Buck T, Bachmann HS, Siffert W, Heusch G, Erbel R (2013) Risk factors for thrombus formation on the Amplatzer Cardiac 
Plug after left atrial appendage occlusion. JACC Cardiovasc Interven 6(6):606-613. https://doi.org/10.1016/j.jcin.2013.02.014

10. Reddy VY, Sievert H, Halperin J, Doshi SK, Buchbinder M, Neuzil P, Huber K, Whisenant B, Kar S, Swarup V, Gordon N, Holmes D, Committee PAS, Investigators (2014) Percutaneous left atrial appendage closure vs warfarin for atrial fibrillation: a randomized clinical trial. JAMA 312(19):1988-1998. https://doi.org/10.1001/ jama.2014.15192

11. Mahajan R, Brooks AG, Sullivan T, Lim HS, Alasady M, Abed HS, Ganesan AN, Nayyar S, Lau DH, Roberts-Thomson KC, Kalman JM, Sanders P (2012) Importance of the underlying substrate in determining thrombus location in atrial fibrillation: implications for left atrial appendage closure. Heart (British Cardiac Society) 98(15):1120-1126. https://doi.org/10.1136/heart jnl-2012-301799

12. Tzikas A, Holmes DR Jr, Gafoor S, Ruiz CE, Blomstrom-Lundqvist C, Diener HC, Cappato R, Kar S, Lee RJ, Byrne RA, Ibrahim R, Lakkireddy D, Soliman OI, Nabauer M, Schneider S, Brachman J, Saver JL, Tiemann K, Sievert H, Camm AJ, Lewalter T (2016) Percutaneous left atrial appendage occlusion: the Munich consensus document on definitions, endpoints and data collection requirements for clinical studies. EuroIntervention 12(1):103-111. https://doi.org/10.4244/EIJV12I1A18

13. Fastner C, Nienaber CA, Park JW, Brachmann J, Zeymer U, Goedde M, Sievert H, Geist V, Lewalter T, Krapivsky A, Kaunicke M, Maier J, Ozdemir B, Hochadel M, Schneider S, Senges J, Akin I (2018) Impact of left atrial appendage morphology on indication and procedural outcome after interventional occlusion: results from the prospective multicentre German LAARGE registry. EuroIntervention 14(2):151-157. https://doi.org/10.4244/ eij-d-17-00866

14. Lip GY, Nieuwlaat R, Pisters R, Lane DA, Crijns HJ (2010) Refining clinical risk stratification for predicting stroke and thromboembolism in atrial fibrillation using a novel risk factorbased approach: the euro heart survey on atrial fibrillation. Chest 137(2):263-272. https://doi.org/10.1378/chest.09-1584

15. Prom R, Usedom JE, Dull RB (2014) Antithrombotics in heart failure with reduced ejection fraction and normal sinus rhythm: an evidence appraisal. Ann Pharmacother 48(2):226-237. https:// doi.org/10.1177/1060028013511058

16. Holmes DR, Reddy VY, Turi ZG, Doshi SK, Sievert H, Buchbinder M, Mullin CM, Sick P (2009) Percutaneous closure of the left atrial appendage versus warfarin therapy for prevention of stroke in patients with atrial fibrillation: a randomised noninferiority trial. Lancet (London, England) 374(9689):534-542. https://doi.org/10.1016/s0140-6736(09)61343-x

17. Holmes DR Jr, Kar S, Price MJ, Whisenant B, Sievert H, Doshi SK, Huber K, Reddy VY (2014) Prospective randomized evaluation of the Watchman Left Atrial Appendage Closure device in patients with atrial fibrillation versus long-term warfarin therapy: the PREVAIL trial. J Am Coll Cardiol 64(1):1-12. https://doi. org/10.1016/j.jacc.2014.04.029

18. Sardi GL, Gaglia MA Jr, Maluenda G, Torguson R, LaynezCarnicero A, Ben-Dor I, Hauville C, Xue Z, Suddath WO, Kent KM, Satler LF, Pichard AD, Lindsay J, Waksman R (2012) Outcome of percutaneous coronary intervention utilizing drug-eluting stents in patients with reduced left ventricular ejection fraction. Am J Cardiol 109(3):344-351. https://doi.org/10.1016/j.amjca rd.2011.09.016

19. Boersma LV, Schmidt B, Betts TR, Sievert H, Tamburino C, Teiger E, Pokushalov E, Kische S, Schmitz T, Stein KM, Bergmann MW, E Investigators (2016) Implant success and safety of left atrial appendage closure with the WATCHMAN device: periprocedural outcomes from the EWOLUTION registry. Eur Heart J 37(31):2465-2474. https://doi.org/10.1093/eurheartj/ehv730

20. Tzikas A, Shakir S, Gafoor S, Omran H, Berti S, Santoro G, Kefer J, Landmesser U, Nielsen-Kudsk JE, Cruz-Gonzalez I, Sievert H, Tichelbacker T, Kanagaratnam P, Nietlispach F, Aminian A, Kasch F, Freixa X, Danna P, Rezzaghi M, Vermeersch P, Stock F, Stolcova M, Costa M, Ibrahim R, Schillinger W, Meier B, Park JW (2016) Left atrial appendage occlusion for stroke prevention in atrial fibrillation: multicentre experience with the AMPLATZER Cardiac Plug. EuroIntervention 11(10):1170-1179. https://doi. org/10.4244/EIJY15M01_06 